\title{
ENTREVISTA COM A PSICÓLOGA, TERAPEUTA SEXUAL E DE CASAIS, E NEUROPSICÓLOGA RAQUEL SIMONE VARASCHIN
}

\author{
por Tereza Cristina Pereira Carvalho Fagundes
}

\begin{abstract}
Raquel Simone Varaschin - Psicóloga pela Pontificia Universidade Católica do Paraná (PUCPR), Pós-Graduada em Sexualidade Humana pela Sociedade Educacional Tuiuti e em Neuropsicologia pelo Instituto Brasileiro de Neuropsicologia e Ciências Cognitivas (IBNeuro). É membro da International Society for Sexual Medicine (ISSM), da Sociedad Latino-Americana para el Estudio de la Impotencia y la Sexualidad (SLAMS), Membro do Comitê de Nomenclatura Sexológica da Federación Latinoamericana de Sociedades de Sexología y Educación Sexual (FLASSES) e membro do Conselho Deliberativo da Sociedade Brasileira em Estudos em Sexualidade Humana (SBRASH). Exerce a função de psicoterapeuta, terapeuta de casal, terapeuta sexual, e neuropsicóloga, no Centro Integrado de Psicologia - Pato Branco-Paraná.
\end{abstract}

Olá Raquel, você é psicóloga, terapeuta sexual e de casais, e neuropsicóloga. Como se deu sua escolha profissional?

Minha escolha profissional pela formação em psicologia se deu naturalmente, percebendo o meu interesse pelo ser humano nas suas diversas facetas, sua dinâmica funcional, patologias e o sofrimento perpetrado, bem como o contexto social onde vive, incluindo questões de diversidade e violência.

Concluí minha formação há 35 anos pela PUC-PR, e ao iniciar atendimento clínico, observei queixas frequentes relacionadas à sexualidade, o que trouxe a necessidade de complementar minha formação. Inicialmente fui autodidata até a realização da primeira Pós-Graduação em Sexualidade Humana, em Curitiba-PR, pela Universidade Tuiuti. Entre os profissionais envolvidos para esta formação estavam Araguari Chalar Silva, Maria do Carmo Andrade Silva, Jorge José Serapião, Paulo Canella.

A partir do momento que iniciei intervenções em sexologia clínica, procurei aprofundar conhecimentos em terapia de casal. Essa formação aconteceu no instituto de Terapia e Centro de Estudos da Família, de abordagem sistêmica, em Curitiba, Paraná. Esse passo foi importante, especialmente considerando que queixas sexuais estão inseridas em um contexto mais amplo - as diversas matizes de um relacionamento além da história individual.

Recentemente, realizei uma pós-graduação e especialização em neuropsicologia, pelo Instituto Brasileiro de Neuropsicologia e Ciências Cognitivas. Estamos vivendo um aumento na expectativa de vida, e temos que considerar as mudanças decorrentes do envelhecimento e que podem comprometer qualidade de vida de idosos, por doenças crônicas, distúrbios neurocognitivos, problemas sociais, entre outros. E tais condições exigem uma avaliação mais criteriosa para uma intervenção mais adequada desta população, incluindo as queixas sexuais.

\section{Que teóricos balizam sua atuação profissional?}

Minha formação foi abrangente, incluindo estudos em psicanálise, terapia cognitiva-comportamental, psicodrama psicoterapêutico e abordagem sistêmica.

Na linha psicanalítica, apesar das críticas a Sigmund Freud, sabemos da importância de determinados conceitos, como mecanismos de defesa do ego, análise dos sonhos, atos falhos, o inconsciente, entre outros. Carl Gustav Jung, que rompeu com Freud, trouxe à luz temas como inconsciente coletivo, sincronicidade e arquétipos. Adolf Adler balizou a auto-responsabilidade sobre atitudes e comportamentos, independente da história pregressa do paciente. Jacques Lacan nos instigou a pensar sobre os sistemas de significação, a linguística, trazendo uma releitura do inconsciente Freudiano. Melanie Klein propôs os jogos, a pintura, o lúdico, como outras formas de expressão das emoções, para o tratamento de crianças e adolescentes.

$\mathrm{Na}$ linha cognitiva-comportamental, temos o fundador, Aaron Beck, neurologista e psiquiatra norte-americano. E hoje tenho acompanhado as pesquisas de Aristides Cordioli, que estão voltadas tanto para trabalhos individuais como em grupo, especialmente em transtornos obsessivos-compulsivos.

No psicodrama psicoterapêutico, criado pelo psiquiatra Jacob Levy Moreno, saímos do método verbal para o método da ação, onde a representação se faz no aqui e agora. Essa variante se mostra importante para o tratamento de casais, principalmente em casos nos quais 
processos inconscientes produzem ou mantêm resistências que interferem na evolução do tratamento.

$\mathrm{Na}$ abordagem sistêmica, que teve sua origem na terapia familiar e foi baseada na Teoria Geral dos Sistemas, formulada pelo biólogo austríaco e filósofo Ludwig Von Bertalanffy temos o emprego de causalidade circular em que ações, comportamentos, relações acontecem dentro de um padrão interativo, também importante para o estudo e avaliação dos casais. Atualmente, estou estudando a Terapia dos Movimentos Sistêmicos, que está sendo formulada por Eduardo Lomando e Claudia Sigaran, cuja terapia integra as abordagens sistêmica, cognitiva-comportamental e narrativa.

Todo esse processo me instrumentou para uma visão holística. A minha prática clínica tem reforçado a necessidade de se adaptar diferentes modelos teóricos às necessidades e desejos de cada paciente, bem como seus limites e demandas.

\section{Como a SBRASH entrou em sua vida?}

Foi no $\mathrm{V}$ Encontro Nacional de Sexologia, em Gramado, RS, em 1987, organizado pela Febrasgo, onde conheci vários profissionais, dentre eles Oswaldo Rodrigues Junior, que, mais tarde, me apresentou à SBRASH, fundada um ano depois da realização deste evento.

Conheci os objetivos da instituição, que incentivava e incentiva estudos e pesquisas em sexualidade, a publicação de artigos, a realização de eventos para atualização de conhecimentos, com extrema preocupação ética. Foi impossível não me encantar pelos movimentos que a instituição estava realizando e que vinham de encontro às minhas necessidades e interesses profissionais.

É um casamento que dura mais de 30 anos, e me sinto motivada em continuar atendendo a missão e objetivos da SBRASH, seja na área social, educacional e/ou na área de saúde, somando esforços para a continuidade do desenvolvimento da Sexologia no Brasil e nos cuidados éticos do exercício desta ciência.

Que importância tem em ser associada da SBRASH? E ter exercido vários cargos, inclusive o de presidente da associação para o dia a dia de sua atuação profissional como psicóloga, neuropsicóloga e terapeuta sexual e de casal?

Ser associada da SBRASH permite que eu continue me aperfeiçoando, me atualizando, estimula a discussão de vários tópicos em diversas áreas da sexualidade e o intercâmbio com diversos profissionais da sexologia, dentro e fora do Brasil. Ter sido presidente da SBRASH, gestão 2018/2019, agregou ainda mais conhecimentos. Tive a oportunidade de observar e constatar o quanto os seus dirigentes continuam o trabalho de seus fundadores, lutando por uma Sexologia que reflita ações sérias, éticas, e que seja respeitada como ciência.

Não foi fácil administrar todas as responsabilidades relacionadas às minhas atividades laborais e exercer cargos institucionais, mas quando somos apaixonados pelo que fazemos e pelo o que acreditamos, não há empecilhos para alcançarmos objetivos. Contribuir com nossa entidade foi recompensador, e agradeço todos os associados e à equipe de trabalho, que foram e são fundamentais $\mathrm{e}$ imprescindíveis nesta jornada pelo saber.

\section{Que temas da Sexologia você mais gosta de estu- dar, ler e escrever?}

Todos os temas provocam meu interesse, mas principalmente tópicos relacionados à área clínica, que é o campo no qual eu atuo - disfunções sexuais, questões de gênero, diversidade sexual, abuso e violência sexual, reprodução assistida e sexualidade, pornografia, psicopatologias, demência, práticas de relacionamento. Minha produção textual é focada em disfunções sexuais, diversidade sexual, psicopatologias, abuso e violência sexual, relacionamentos na era digital, câncer de mama e sexualidade, entre outros tópicos.

\section{Como avalia o estudo e as práticas da Sexologia no Brasil?}

A sexologia no Brasil passou por ciclos de desenvolvimento a partir do século XIX. A sexualidade teve suas raízes em movimentos de eugenismo e higienismo no discurso médico, em que a saúde sexual significava presunções de indivíduos mentalmente saudáveis. Voltava-se atenção para patologização de práticas sexuais, e a sexualidade sendo tratada com fins reprodutivos e evolutivos.

Por outro lado, o andrologista José de Albuquerque, pioneiro na Sexologia no Brasil, escreveu e propôs educação sexual na escola já na década de 30 , desenvolvendo estratégias no combate às doenças venéreas, às perversões sexuais e aos preconceitos sobre a sexualidade. $\mathrm{Na}$ época, Albuquerque defendeu o controle da natalidade, aborto terapêutico e divórcio.

Em nossa história tivemos a influência da "cultura psicanalítica", com Freud, Lacan, Foucault, entre outros, e depois de uma "cultura alternativa", com as teorias de Wilhelm Reich, cujos tratamentos sexuais eram considerados controversos. E Para muitos Reich foi considerado o inspirador para a "revolução sexual". Segue o movimento de institucionalização da Sexologia no Brasil, e, em 1959 é criada a Federação Brasileira de Associações de Ginecologia e Obstetrícia (Febrasgo), cujo foco era a saúde sexual feminina.

Na década de 1970, outros trabalhos foram publicados, e não teríamos apenas a influência da teoria 
psicanalítica nos estudos da sexualidade humana, mas também da abordagem comportamental, com os trabaIhos de Masters e Johnson.

Em 1988 pensou-se em uma Sociedade que pudesse contemplar saberes multidisciplinares no estudo da sexualidade. Desta necessidade nasceu a Sociedade Brasileira de Estudos em Sexualidade Humana (SBRASH), com a missão de "incentivar o desenvolvimento da sexualidade humana em âmbito nacional, por meio do intercâmbio científico entre os profissionais interessados no estudo das diferentes dimensões da sexualidade, zelando pela preservação dos valores éticos na execução de atividades especializadas na área".

Na década de 1990, a urologia desenvolveu pesquisas e ações de intervenção relacionadas às disfunções sexuais masculinas, numa perspectiva mais biomédica. Mais tarde passou adotar uma visão transdisciplinária, e, gradativamente, introduziu discussões multidisciplinares em eventos de medicina sexual.

Paralelamente a estes acontecimentos, nasceu o movimento LGBT, em um período de grande repressão - de ditadura miliar - entre 1964 a 1985. Houveram algumas publicações, como o Jornal Lampião da Esquina. Nos anos 1980, a entidade se reorganizou e se fortaleceu para enfrentar os desafios que vieram com o advento da AIDS. Em 198I, o Grupo Gay da Bahia iniciou campanha a nível nacional de despatologização da homossexualidade. A partir da década de 1990, o movimento obteve maior visibilidade com as Paradas de Orgulho LGBT e na luta pelos direitos civis, humanos e sexuais. Mais tarde, novas conquistas são realizadas pelo movimento: a legalização do casamento entre homossexuais, a despatologização da identidade trans, a autorização da redesignação sexual, a utilização do nome social e as mudanças de registro civil para a população de transexuais e travestis.

Infelizmente, apesar de processo evolutivo da Sexologia no Brasil, do eugenismo/higienismo à medicalização e à uma visão holística, nos deparamos com o aumento nos índices de gravidez na adolescência, do feminicídio, do abuso e violência sexual, das IST (Sífilis, HIV/AIDS, HPV) e da LBGTfobia.

Vejo que parte deste resultado é consequência de retaliações de grupos que cerceiam a educação em sexualidade, em função de uma pretensa ideologia advinda de movimentos sociopolíticos. Como bem define Marilene Chaú "Ideologia, é um conjunto lógico, sistemático e coerente de representações (ideias e valores) de normas ou regras (de conduta) que indicam e prescrevem aos membros da sociedade o que devem pensar, o que devem valorizar e como devem valorizar, o que devem sentir e como devem sentir, o que devem fazer e como devem fazer". (1983)
Você sempre participa dos congressos internacionais e tem muitas relações com colegas de outros países, principalmente da América Latina. Como avalia a sexologia no Brasil, em relação aos nossos irmãos mais próximos, de língua espanhola?

A minha participação em congressos internacionais estreitou relações com profissionais em sexologia de outros países. Neste intercâmbio, observei como as diferenças políticas, socioeconômicas e religiosas de cada país geram consequências para a sociedade científica na condução de estudos e pesquisas, ou mesmo de ações, principalmente na área educacional.

Alain Giami (INSERM) e Jane Russo (CLAM) realizaram uma pesquisa sobre "Sexualidade, Ciência e Profissão na América Latina”, que analisou a situação da sexologia na Argentina, Brasil, Chile, Colômbia, México e Peru. No artigo "Novas Tecnologias de Intervenções na Sexualidade: O panorama latino-americano", no qual os autores Alain Giami, Jane Russo e Fabíola Rohden (2014) comentam sobre a pesquisa realizada, observaram que apesar de diferenças, esses seis países apresentam questões comuns em Sexologia como: a falta de uma certificação hegemonicamente validada; a dificuldade de inserção de profissionais especialistas no setor público seja na saúde ou educação; a medicina sexual com uma concepção biomédica das disfunções sexuais, diferenciando-se da clínica de visão tradicional e humanista; a medicalização da sexualidade para o ideal performático; e a educação com uma perspectiva mais construtivista - discutindo reprodução, diversidade e direitos sexuais - associando-se muitas vezes a movimentos sociais o feminismo e o LBGTI+.

No Brasil especificamente, o governo tem apresentado uma compreensão da sexualidade que, muitas vezes, se opõe aos preceitos científicos, quando discutem ou tomam decisões relacionadas às questões de gênero, orientação sexual, iniciação sexual ou diversidade. E deflagram-se atitudes que tem violado os direitos sexuais e reprodutivos, comprometendo a saúde afetiva e sexual da população em geral. Além disso, a discussão em Sexologia tem se apresentado de forma segmentada, perdendo-se a visão multidisciplinar.

\section{Um conselho para a próxima presidente da SBRASH}

No momento histórico atual, instituições como a SBRASH são fundamentais na preservação cientifica do campo de sexologia no Brasil. Por isso, se faz necessário ampliar a força-tarefa para regularizar o exercício da sexologia como ciência e como profissão, executar ações de inclusão da educação em sexualidade, criar espaços de discussão, proporcionar saúde sexual em diversos setores, e reunir-se com representantes de conselhos profissionais 
68 Revista Brasileira de

Sexualidade Humana

DOI: https://doi.org/10.35919/rbsh.v30i2.93

e outras sociedades científicas, na busca de parcerias para o fortalecimento na luta pelos direitos sexuais e humanos, pelo combate à discriminação e para a promoção da saúde sexual e educação em sexualidade para todos.

Tereza Cristina Fagundes

Pedagoga, mestra e doutora em Educação

Professora da Universidade Federal da Bahia (UFBA)

Diretora de Relacionamento da SBRASH (20I8-202I)

Membro da Comisión de Educación y Formación

Continua de FLASSES (2018-2020) 